\title{
PENENTUAN PENILAIAN KREDIT MENGGUNAKAN METODE NAIVE BAYES BERBASIS PARTICLE SWARM OPTIMIZATION
}

\author{
Rinawati \\ Sekolah Tinggi Manajemen Informatika dan Komputer Nusa Mandiri \\ (STMIK Nusa Mandiri) \\ Jl. Kramat Raya No.18 Jakarta Pusat \\ http://www.nusamandiri.ac.id \\ rinawati.riw@nusamandiri.ac.id
}

\begin{abstract}
Abstrak
Kredit macet merupakan salah satu resiko kredit yang dihadapi oleh pelaku industri keuangan dan perbankan. Kredit macet dapat dihindari dengan cara melakukan analisa kredit yang akurat terhadap calon debitur. Keakuratan penilaian kredit sangat penting untuk profitabilitas lembaga keuangan. Peningkatan akurasi penilaian kredit dapat dilakukan dengan cara melakukan seleksi terhadap atribut, karena seleksi atribut mengurangi dimensi dari data sehingga operasi algoritma data mining dapat berjalan lebih efektif dan lebih cepat.Banyak penelitian yang telah dilakukan untuk penentuan penilaian kredit. Salah satu metode yang paling banyak digunakan adalah metode Naive Bayes. Dalam penelitian ini akan digunakan metode Naive Bayes dan akan dilakukan seleksi atribut dengan menggunakan particle swarm optimization untuk penentuan penilaian kredit. Setelah dilakukan pengujian maka hasil yang didapat adalah Naive Bayes menghasilkan nilai akurasi sebesar 72,40 \% dan nilai AUC sebesar 0,765. Kemudian dilakukan optimasi dengan menggunakan particle swarm optimization hasil menunjukkan nilai akurasi yang lebih tinggi yaitu sebesar 75,90\% dan nilai AUC sebesar 0,773. Sehingga dicapai peningkatan akurasi sebesar 3,5\%, dan peningkatan AUC sebesar 0,008. Dengan melihat nilai akurasi dan AUC, maka algoritma Naive Bayes berbasis particle swarm optimization masuk kedalam kategori klasifikasi cukup.
\end{abstract}

Kata kunci: Penilaian Kredit, Seleksi Atribut, Naive Bayes , Particle Swarm Optimization

\begin{abstract}
Bad credit is one of the credit risk faced by the financial and banking industry. Bad credit can be avoided by means of an accurate credit analysis of the debtor. The accuracy of credit ratings is crucial to the profitability of financial institutions. Improved accuracy of credit ratings can be done by doing the selection of attributes, because the selection of attributes reduce the dimensionality of the data so that operation of the data mining algorithms can be run more effectively and more cepat.Banyak research has been conducted to determine credit ratings. One of the methods most widely used method of Naive Bayes. In this study will be used method Naive Bayes and will do the selection of attributes by using particle swarm
\end{abstract}


optimization to determine credit ratings. After testing the results obtained are Naive Bayes produce accuracy value of $72.40 \%$ and AUC value of 0.765 . Then be optimized by using particle swarm optimization results show values higher accuracy is equal to 75.90\% and AUC value of 0.773. So as to achieve the increased accuracy of 3.5\%, and increased the AUC of 0.008. By looking at the accuracy and AUC values, the Naive Bayes algorithm based on particle swarm optimization into the classification category enough.

Keywords: Credit scoring, Attributes Selection, Naive Bayes, Particle Swarm Optimization

\section{PENDAHULUAN}

Penilaian kredit merupakan hal yang penting dalam pengelolaan resiko keuangan. Laporan bank Indonesia menunjukkan bahwa pada akhir tahun 2011 tercatat kredit macet senilai Rp. 33.401.000.000.000 naik hingga 17,64\% dibandingkan dengan th 2010 sebesar Rp. 28.396.000.000.000 [1]. Hal tersebut menunjukkan bahwa tingkat kredit macet mengalami kenaikan yang tajam. Kredit macet dapat dihindari dengan cara melakukan analisa kredit yang akurat terhadap calon debitur [2]. Tujuan utamanya adalah untuk memperoleh keyakinan bahwa debitur akan dapat memenuhi setiap kewajibannya dan memastikan kualitas kredit tetap lancar sampai berakhirnya perjanjian kredit. Keakuratan penilaian kredit sangat penting untuk profitabilitas lembaga keuangan [3]. Penilaian kredit mengelompokkan para calon debitur menjadi dua jenis yaitu debitur baik dan debitur buruk. Debitur baik memiliki kemungkinan besar akan membayar kewajiban keuangannya dengan lancar, sedangkan debitur buruk memiliki kemungkinan besar mengalami kredit macet [3]. Penilaian kredit sangat penting karena banyak keuntungan yang diperoleh yaitu mengurangi biaya analisa kredit, pengambilan keputusan lebih cepat, pemantauan lebih dekat dengan data yang ada dan memungkinkan untuk menetapkan calon debitur prioritas [4]. Penilaian kredit juga bermanfaat bagi penyedia kredit untuk mengukur dan mengelola risiko keuangan dalam memberikan kredit sehingga mereka dapat membuat keputusan yang lebih baik, lebih cepat dan lebih obyektif [5].

Seleksi fitur adalah langkah untuk memilih dan mendapatkan informasi yang lebih berharga dari data dengan fitur yang besar. Atribut dan informasi yang berlebihan yang dimasukkan kedalam model penilaian kredit mengakibatkan banyaknya waktu dan biaya yang dikorbankan bahkan akan mengurangi tingkat akurasi dan kompleksitas yang lebih tinggi. Untuk itu diperlukan metode seleksi atribut pada data set dengan jumlah atribut yang besar untuk meningkatkan hasil akurasi [4].

Naive Bayes adalah pengklasifikasian statistik yang dapat digunakan untuk memprediksi probabilitas keanggotaan suatu class. Naive Bayes didasarkan pada teorema Bayes yang memiliki kemampuan klasifikasi serupa dengan decision tree dan neural network. Naive Bayes terbukti memiliki akurasi dan kecepatan yang tinggi saat diaplikasikan kedalam database dengan data yang besar [6]. 
Particle swarm optimization (PSO) merupakan teknik komputasi evolusioner yang mampu menghasilkan solusi optimal secara global dalam ruang pencarian melalui interaksi individu dalam segerombolan partikel. Setiap partikel menyampaikan informasi berupa posisi terbaiknya kepada partikel yang lain dan menyesuaikan posisi dan kecepatan masing-masing berdasarkan informasi yang diterima mengenai posisi yang terbaik tersebut [7]. Particle swarm optimization dapat digunakan sebagai teknik optimasi untuk mengoptimalkan subset fitur dan parameter secara bersamaan [8]. Algoritma PSO sederhana dan memiliki kompleksitas yang lebih rendah. sehingga dapat memastikan solusi optimal dengan menyesuaikan pencarian global dan lokal, sehingga kinerja klasifikasi SVM dapat ditingkatkan [8]. Melihat kemampuan dari metode Particle swarm optimization (PSO) tersebut, maka pada penelitian ini metode Particle swarm optimization (PSO) akan diterapkan untuk seleksi atribut dalam penentuan penilaian kredit sehingga akan diperoleh peningkatan akurasi.

\section{METODE PENELITIAN}

\subsection{Tinjauan Pustaka}

\subsubsection{Penilaian Kredit}

Menurut UU Perbankan No.10 Tahun 1998 Pasal 1 Ayat 11 menyatakan bahwa kredit adalah penyediaan uang atau tagihan yang dapat dipersamakan dengan itu, berdasarkan persetujuan atau kesepakatan pinjam-meminjam antara bank dengan pihak lain yang mewajibkan pihak peminjam untuk melunasi utangnya setelah jangka waktu tertentu dengan pemberian bunga. Penilaian kredit didefinisikan sebagai teknik dan model keputusan yang mendasari penyedia kredit memutuskan masalah pemberian kredit kepada konsumen [9].

\subsubsection{Seleksi Atribut}

Seleksi atribut adalah masalah terkait erat dengan pengurangan dimensi. Tujuan seleksi atribut adalah untuk mengidentifikasi tingkat kepentingan atribut dalam kumpulan data, dan membuang semua atribut lain seperti informasi yang tidak relevan dan berlebihan. Karena seleksi atribut mengurangi dimensi dari data, maka hal ini akan memungkinkan operasi algoritma data mining dapat berjalan lebih efektif dan lebih cepat. Dalam beberapa kasus dengan dilakukannya seleksi atribut dihasilkan peningkatan tingkat akurasi klasifikasi [10].

\subsubsection{Naive Bayes}

Metode Naive Bayes pertama kali dikenalkan oleh ilmuwan Inggris Thomas Bayes yang digunakan untuk memprediksi peluang yang terjadi di masa depan berdasarkan pengalaman di masa sebelumnya sehingga dikenal sebagai teorema Bayes. Algoritma Naive Bayes merupakan suatu bentuk klasifikasi data dengan menggunakan metode probabilitas dan statistik. Algoritma Naive Bayes dapat diartikan sebagai sebuah metode yang tidak memiliki aturan, Naive Bayes menggunakan cabang matematika yang dikenal dengan teori probabilitas untuk mencari peluang terbesar dari kemungkinan klasifikasi dengan cara melihat frekuensi tiap klasifikasi pada data training. Metode Teorema bayes kemudian 
dikombinasikan dengan naive yang diasumsikan dengan kondisi antar atribut yang saling bebas.

\subsubsection{Algoritma Particle Swarm Optimization}

Algoritma Particle swarm optimization (PSO) pertama kali diusulkan oleh Kennedy dan Eberhart pada tahun 1995. Particle swarm optimization (PSO) adalah jenis algoritma kecerdasan yang berasal dari perilaku kawanan burung mencari makan [8]. Particle swarm optimization (PSO) merupakan teknik komputasi evolusioner yang mampu menghasilkan solusi secara global optimal dalam ruang pencarian melalui interaksi individu dalam segerombolan partikel. Setiap partikel menyampaikan informasi berupa posisi terbaiknya kepada partikel yang lain dan menyesuaikan posisi dan kecepatan masing-masing berdasarkan informasi yang diterima mengenai posisi yang terbaik tersebut [7]. Particle swarm optimization (PSO) dapat diasumsikan dengan sekelompok burung yang secara acak mencari makanan di suatu daerah. Hanya ada satu potong makanan di daerah yang dicari tersebut. Burung-burung tidak tahu di mana makanan tersebut. Tapi mereka tahu seberapa jauh makanan tersebut dan posisi rekan-rekan mereka. Jadi strategi terbaik untuk menemukan makanan adalah dengan mengikuti burung yang terdekat dari makanan [11].

\subsection{Desain Penelitian}

Penelitian ini menggunakan penelitian eksperimen. Penelitian eksperimen melibatkan penyelidikan perlakuan pada parameter atau variabel tergantung dari penelitinya dan menggunakan tes yang dikendalikan oleh si peneliti itu sendiri. Dengan metode penelitian sebagai berikut:

1. Pengumpulan data

Pada tahap ini ditentukan data yang akan diproses. Mencari data yang tersedia, memperoleh data tambahan yang dibutuhkan, mengintegrasikan semua data kedalam data set, termasuk variabel yang diperlukan dalam proses.

2. Pengolahan data awal

Pada tahap ini dijelaskan tentang tahap awal data mining. Pengolahan awal data meliputi proses input data ke format yang dibutuhkan, pengelompokan dan penentuan atribut data, serta pemecahan data (split) untuk digunakan dalam proses pembelajaran (training) dan pengujian (testing).

3. Metode yang diusulkan

Pada tahap ini data dianalisis, dikelompokan variabel mana yang berhubungan satu sama lainnya. Setelah data dianalisis lalu diterapkan model-model yang sesuai dengan jenis data. Pembagian data kedalam data latihan (training data) dan data uji (testing data) juga diperlukan untuk pembuatan model.

4. Eksperimen dan pengujian metode

Pada tahap ini akan dilakukan eksperimen meliputi cara pemilihan arsitektur yang tepat dari metode yang diusulkan sehingga didapatkan hasil yang dapat membuktikan bahwa metode yang digunakan adalah tepat.

5. Evaluasi dan validasi hasil 
Pada tahap ini dilakukan evaluasi dan validasi hasil penerapan terhadap model penelitian yang dilakukan untuk mengetahui tingkat keakurasian model.

\subsection{Pengumpulan Data}

Data yang diperoleh adalah data sekunder karena diperoleh dari data kredit German database dalam UCI machine learning responsitory. Data kredit German merupakan data publik karena data tersebut dipublikasikan dan data tersebut dapat diakses oleh siapa saja. Masalah yang harus dipecahkan di sini adalah penentuan penilaian kredit dari 1.000 nasabah 700 diidentifikasi sebagai nasabah yang baik dan 300 merupakan nasabah buruk. Terdiri dari 21 atribut. Variabel tersebut ada yang tergolong variabel prediktor atau pemrediksi yaitu variabel yang dijadikan sebagai penentu hasil penilaian kredit, dan variabel tujuan yaitu variabel yang dijadikan sebagai hasil penilaian kredit. Adapun variabel prediktor yaitu: checking account, Duration, history, Purpose, amount, Savings account, Present employment since, Installment rate in percentage of disposable income, Personal status and sex, Other debtors/guarantors, Present residence since, Property, Age in years, Other installment plans, Housing, Number of existing credits at this bank, Job, Number of people being liable to provide maintenance for, Telephone, foreign worker. Sedangkan variabel tujuannya yaitu Response [12].

\subsection{Pengolahan data awal}

Jumlah data awal yang diperoleh dari pengumpulan data yaitu sebanyak 1.000 data, namun tidak semua data dapat digunakan dan tidak semua atribut digunakan karena harus melalui beberapa tahap pengolahan awal data (preparation data). Untuk menghilangkan duplikasi dan inkonsistensi data, maka dilakukan replace missing.

\begin{tabular}{|c|c|c|c|c|c|}
\hline Role & Name & Tipe & Staisitics & Range & Missings \\
\hline |abel & RESPONSE & binominal & mode $=1(700)$, least $=2(300)$ & $1(700), 2(300)$ & 0 \\
\hline regular & cheding account & integer & $a 19=2577+1-1258$ & {$[1.000 ; 4.000]$} & 0 \\
\hline regylar & Durdion & integer & $a 10=20.903++12059$ & [4000; 72000] & 0 \\
\hline regular & history & integer & $a g y=2545+1.1083$ & {$[0000 ; 4000]$} & 0 \\
\hline regular & Pupose & integer & $a r g=2828+1-2744$ & {$[0.000 ; 10.000]$} & 0 \\
\hline regulart & amount & integer & $a g=3271.258+1-2822737$ & {$[250.000 ;$; 18424 4000] } & 0 \\
\hline regular & Saings scosurt & integer & $a 19=2.105+1-1.580$ & {$[1.000 ; 5000]$} & 0 \\
\hline regular & employment & integer & $a 19=3.384+1-1208$ & {$[1.000 ; 5.0000]$} & 0 \\
\hline regular & Install|mentrate & integer & $a 19=2973+1-1.119$ & {$[1.000 ; 4.000]$} & 0 \\
\hline regylar & status and ser & integer & $a 19=2682++.0 .708$ & {$[1.000 ; 40000]$} & 0 \\
\hline regular & Other deltotos / guararatiors & integer & $a g=1.145+t .0 .478$ & {$[1.000 ; 3.000]$} & 0 \\
\hline regular & Presentriesidences sinces & integer & $a g=2845+1.1 .104$ & {$[1.000 ; 4.000]$} & 0 \\
\hline regular & Property & integer & $a g=2359+1-1.051$ & {$[1.000 ; 4000]$} & 0 \\
\hline regular & Age & integer & $a 19=35.546+11.375$ & {$[190000 ; 750000]$} & 0 \\
\hline regular & Otherinstallment & integer & $a 19=2675+1.0 .706$ & {$[1.000 ; 30000]$} & 0 \\
\hline regular & Housing & integer & $a n=1.229+1.0 .531$ & {$[1000 ; 30000]$} & 0 \\
\hline regular & Number ceeflts & integer & $\arg =1.407+1.0 .578$ & {$[1.000 ; 4000]$} & 0 \\
\hline regular & Job & integer & $a n=2.004+1.0 .654$ & {$[1.000 ; 4.000]$} & 0 \\
\hline regular & Number of perple being libile top & integer & $a g=1.155++.0 .362$ & {$[1.000 ; 2000]$} & 0 \\
\hline regular & Telephnone & integer & $a g=1.404+1-0.491$ & {$[1.000 ; 2000]$} & 0 \\
\hline regular & foreign & integer & $a g=1.037+1-0.189$ & {$[1.000 ; 2000]$} & 0 \\
\hline
\end{tabular}

Gambar 1. Hasil Replace Missing

Dari gambar 1 diatas diketahui bahwa tidak terdapat missing attribute yang terjadi yang berarti semua data dan atribut dapat digunakan dalam pengolahan data. 
Jurnal Sains Komputer \& Informatika (J-SAKTI)

Volume (1) No. 1 Maret 2017

ISSN:2548-9771/EISSN: 2549-7200

http://ejurnal.tunasbangsa.ac.id/index.php/jsakti

\subsection{Metode yang diusulkan}

Metode yang diusulkan pada penelitian ini adalah menggunakan algoritma Naive Bayes dan Particle swarm optimization. Berikut ini bentuk gambaran metode algoritma yang akan diuji.

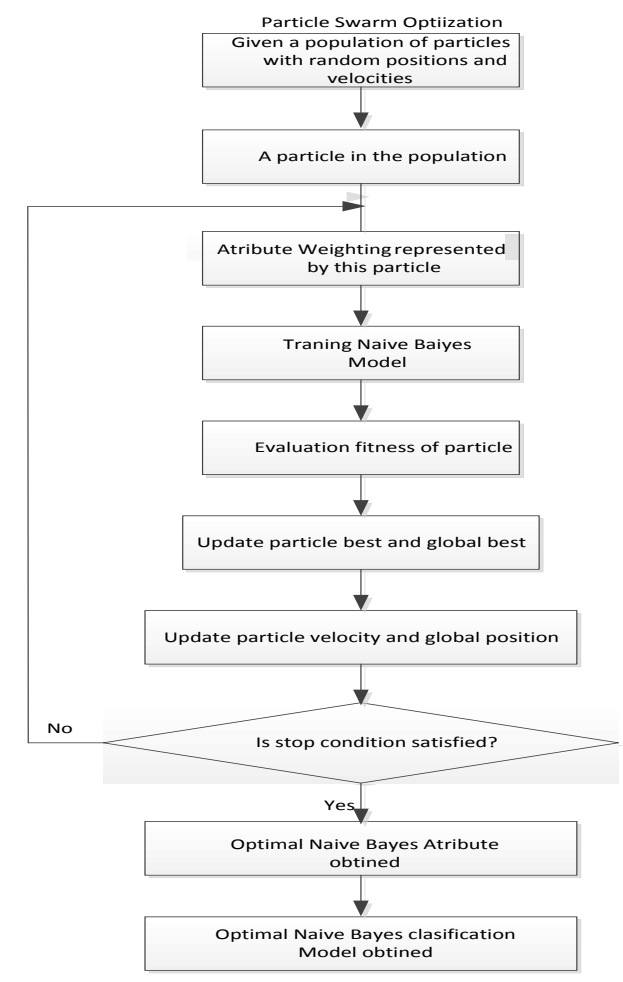

Gambar 2. Metode yang diusulkan

\section{PEMBAHASAN}

\subsection{Hasil Pengujian Metode Naive Bayes}

Hasil dari pengujian metode yang dilakukan adalah untuk menentukan nilai accuracy dan AUC. Metode pengujiannya menggunakan cross validation dengan desain modelnya sebagai berikut.

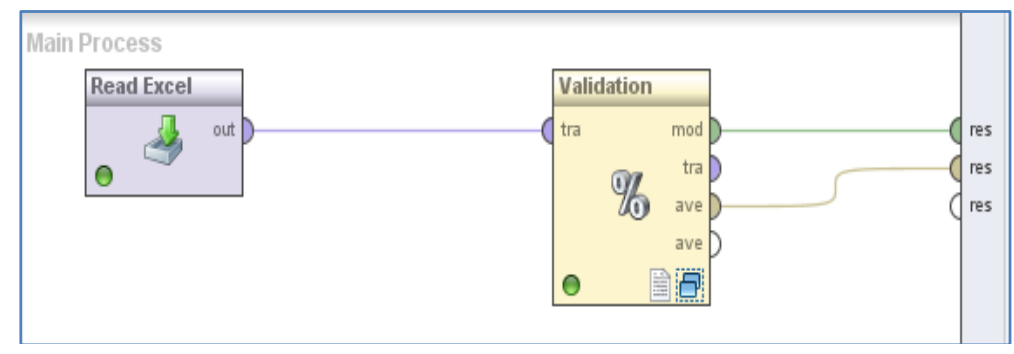

Gambar 3. Desain model Validasi

Pada penelitian penilaian kredit menggunakan algoritma Naive Bayes menggunakan framework RapidMiner sebagai berikut. 


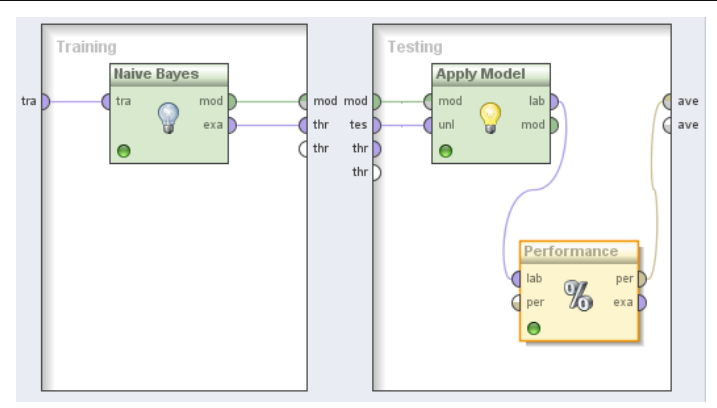

Gambar 4. Model pengujian validasi Naive Bayes

Nilai accuracy, precision, dan recall dari data training dapat dihitung dengan menggunakan RapidMiner.

Tabel 1. Model Confusion Matrix untuk metode Naive Bayes

\begin{tabular}{|c|c|c|c|}
\hline \multicolumn{4}{|c|}{ accuracy:72.40\%+/-6.20\% (mikro: } \\
$\mathbf{7 2 . 4 0 \% )}$ \\
\hline & $\begin{array}{c}\text { True } \\
\text { GOOD }\end{array}$ & $\begin{array}{c}\text { True } \\
\text { BAD }\end{array}$ & $\begin{array}{c}\text { Class } \\
\text { precission }\end{array}$ \\
\hline $\begin{array}{c}\text { pred. } \\
\text { GOOD }\end{array}$ & 533 & 109 & $83.02 \%$ \\
\hline $\begin{array}{c}\text { pred. } \\
\text { BAD }\end{array}$ & 167 & 191 & $53.35 \%$ \\
\hline $\begin{array}{c}\text { class } \\
\text { recall }\end{array}$ & $76.14 \%$ & $63.67 \%$ & \\
\hline
\end{tabular}

Pada Tabel 1 dijelaskan hasil pengujian dengan menggunakan metode Naive Bayes didapatkan hasil Dari 1.000 data, 533 diklasifikasikan GOOD sesuai dengan prediksi yang dilakukan dengan metode Naive Bayes, lalu 109 data diprediksi G00D tetapi ternyata hasilnya BAD, 167 data diprediksi BAD ternyata hasil nya GO0D dan 191 diklasifikasikan BAD sesuai dengan prediksinya.

Hasil perhitungan divisualisasikan dengan kurva ROC. Garis horizontal adalah false positives dan garis vertikal true positives.

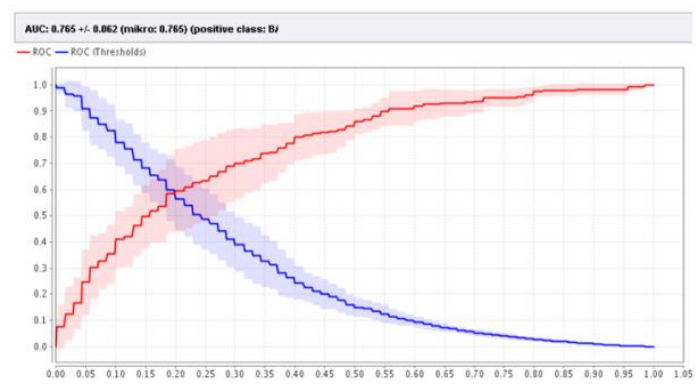

Gambar 5. Kurva ROC dengan metode Naive Bayes 
Dari Gambar 5 terdapat grafik ROC dengan nilai AUC (Area Under Curve) sebesar 0.765 dimana diagnosa hasilnya Fair classification.

Berdasarkan hasil eksperimen yang dilakukan untuk memecahkan masalah penilaian kredit, dapat disimpulkan bahwa hasil eksperimen menggunakan metode Naive Bayes mempunyai tingkat akurasi sebesar $72.40 \%$ dan mempunyai nilai AUC sebesar 0.765 .

\subsection{Hasil Pengujian Model Naive Bayes berbasis Particle swarm optimization}

Pengujian dengan menggunakan metode Naive Bayes berbasis Particle Swarm Optimization pada framework RapidMiner sebagai berikut.

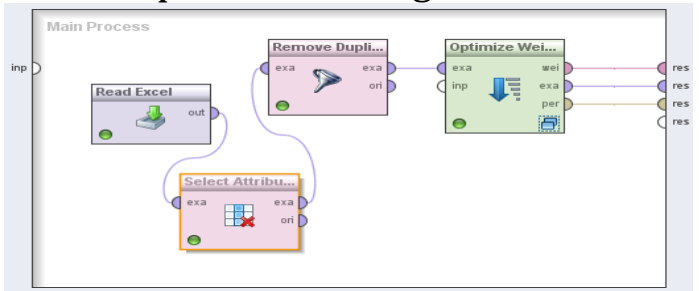

Gambar 6. Desain model Validasi Naive Bayes berbasis PSO

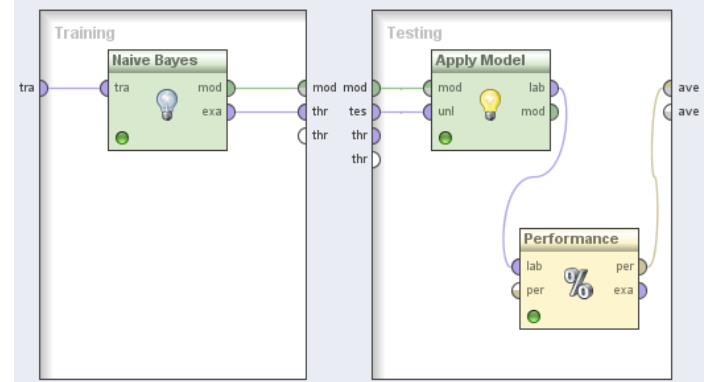

Gambar 7. Modelpengujian Validasi Naive Bayes berbasis PSO

Dari hasil eksperiment diperoleh hasil seleksi atribut seperti dalam Tabel 2 dibawah ini.

Tabel 2. Hasil Seleksi Atribut

\begin{tabular}{|l|l|}
\hline \multicolumn{1}{|c|}{ Atribute } & Weight \\
\hline checking account & 1 \\
\hline Duration & 1 \\
\hline History & 1 \\
\hline Purpose & 1 \\
\hline Amount & 0.995 \\
\hline Savings account & 1 \\
\hline Present employment since & 1 \\
\hline Installment rate in percentage of disposable income & 1 \\
\hline Personal status and sex & 0.603 \\
\hline Other debtors / guarantors & 1 \\
\hline
\end{tabular}


Jurnal Sains Komputer \& Informatika (J-SAKTI)

Volume (1) No. 1 Maret 2017

ISSN:2548-9771/EISSN: 2549-7200

http://ejurnal.tunasbangsa.ac.id/index.php/jsakti

\begin{tabular}{|l|l|}
\hline \multicolumn{1}{|c|}{ Atribute } & Weight \\
\hline Present residence since & 1 \\
\hline Property & 0 \\
\hline Age in years & 0 \\
\hline Other installment plans & 0 \\
\hline Housing & 1 \\
\hline Number of existing credits at this bank & 0.910 \\
\hline Job & 0 \\
\hline Number of people being liable to provide maintenance for & 0 \\
\hline Telephone & 0 \\
\hline foreign worker & 0 \\
\hline
\end{tabular}

Dari Tabel 2 hasil seleksi atribut diperoleh 7 atribute variabel prediktor yang memiliki weight 0 yaitu: Property, Age in years, Other installment plans, Job, Number of people being liable to provide maintenance for, Telephone, foreign worker. Berarti bahwa atribute tersebut tidak memiliki pengaruh terhadap akurasi penilaian kredit, sehingga diperoleh 13 atribut yang digunakan.

Tabel 3. Model Confusion Matrix untuk metode Naive Bayes berbasis Particle Swarm Optimization

\begin{tabular}{|c|c|c|c|}
\hline \multicolumn{4}{|c|}{ accuracy:75.90\% +/-4.46\% (mikro: 75.90\%) } \\
\hline & True GOOD & True BAD & Class precission \\
\hline pred. GOOD & 600 & 141 & $80.97 \%$ \\
\hline pred. BAD & 100 & 159 & $61.39 \%$ \\
\hline class recall & $76.14 \%$ & $63.67 \%$ & \\
\hline
\end{tabular}

Tabel 3 menjelaskan bahwa dari 1.000 data, 600 diklasifikasikan GO0D sesuai dengan prediksi, lalu 141 data diprediksi GOOD tetapi ternyata hasilnya BAD, 100 data diprediksi BAD ternyata hasilnya GOOD,159 diklasifikasikan BAD sesuai dengan prediksi. Dari hasil perhitungan tersebut, kemudian divisualisasikan dengan kurva ROC. Garis horizontal adalah false positives dan garis vertikal true positives.

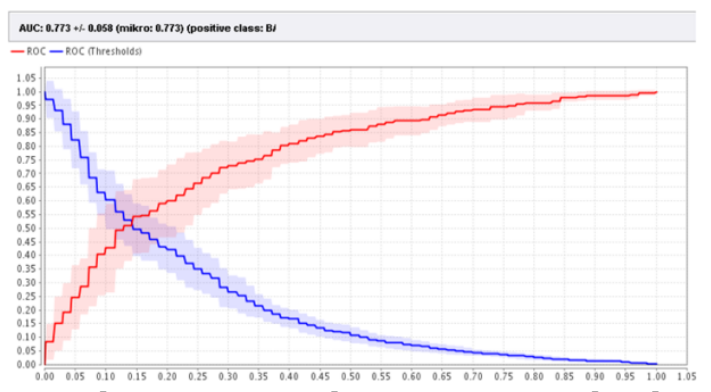

Gambar 8. Kurva ROC dengan metode Naive Bayes berbasis Particle Swarm Optimization 
Dari Gambar 8 terdapat grafik ROC dengan nilai AUC (Area Under Curve) sebesar 0.773 dimana diagnosa hasilnya Fair classification.

Berdasarkan hasil eksperimen yang dilakukan untuk memecahkan masalah penilaian kredit, dapat disimpulkan bahwa hasil eksperimen menggunakan metode Naive Bayes berbasis Particle Swarm Optimization mempunyai tingkat akurasi sebesar $75.90 \%$ dan mempunyai nilai AUC sebesar 0.773 .

Perbandingan hasil antara metode Naive Bayes dengan Naive Bayes berbasis Particle Swarm Optimization dapat dilihat dalam tabel dibawah ini:

Tabel 4. Perbandingan hasil metode Naive Bayes dan Naive Bayes berbasis Particle Swarm Optimization

\begin{tabular}{|c|c|c|}
\hline & Accuracy & AUC \\
\hline Naive Bayes & $72.40 \%$ & 0.765 \\
\hline $\begin{array}{c}\text { Naive Bayes } \\
\text { berbasis PSO }\end{array}$ & $75.90 \%$ & 0.773 \\
\hline
\end{tabular}

\section{SIMPULAN}

Dalam penelitian ini dilakukan pengujian model dengan menggunakan Naive Bayes dan Naive Bayes berbasis Particle Swarm Optimization dengan menggunakan data kredit German. Model yang dihasilkan diuji untuk mendapatkan nilai accuracy dan AUC dari setiap algoritma sehingga didapat pengujian dengan menggunakan Naive Bayes didapat nilai accuracy adalah $72,40 \%$ dan nilai AUC adalah 0.765 . Sedangkan pengujian dengan mengunakan Naive Bayes berbasis Particle Swarm Optimization dilakukan seleksi atribut dari 20 variabel prediktor terpilih 13 atribut yang digunakan, sehingga didapatkan nilai accuracy $75.90 \%$ dan nilai AUC adalah 0.773. Maka dapat disimpulkan pengujian data kredit German UCI data set menggunakan Naive Bayes berbasis Particle Swarm Optimization didapat bahwa metode tersebut lebih akurat dalam penentuan penilaian kredit dibandingkan dengan metode Naive Bayes tunggal, ditandai dengan peningkatan nilai akurasi sebesar 3,5\% dan nilai AUC sebesar 0.008, dengan nilai tersebut masuk kedalam klasifikasi akurasi cukup (fair classification).

Dari hasil pengujian yang telah dilakukan dan hasil kesimpulan yang diberikan maka ada saran atau usul yang di berikan antara lain:

1) Untuk meningkatkan hasil optimasi dapat dilakukan metode pemilihan parameter dengan metode Genetic Algorithm dan lain-lain.

2) Mencoba menerapkan metode optimasi yang lain sebagai bahan perbandingan.

3) Untuk mengetahui kehandalan metode maka pada penelitian selanjutnya dapat dilakukan penggunaan data set lebih dari satu.

\section{DAFTAR PUSTAKA}

[1] B. Indonesia, Juni 2012. [Online]. Available: http://www.bi.go.id/NR/rdonlyres/B03D425D-9BEE-42A7-B500- 


\section{DE7C023507CE/26392/BISPIApril20121.pdf.}

[2] T. Bellotti and J. Crook, "Support Vector Machines For Credit Scoring And Discovery Of Significant Features," Expert System With Application, vol. 36, no. 2, pp. 3302-3308, 2009.

[3] G. Wang, J. Hao, J. Ma and H. Jiang, "A Comparative Assessment Of Ensemble Learning For Credit Scoring," Expert System With Applications: An International Journal, vol. 38, no. 1, pp. 223-230, 2011.

[4] P. Yao, "Feature Selection Based On SVM For Credit Scoring," International Conference on Computational Intelligence and Natural Computing, pp. 44-47, 2009.

[5] H. C. Koh, W. C. Tan and C. P. Goh, "A Two-step Method To Construct Credit Scoring Models With Data Mining Technigues," International Journal of Business and Information, vol. 1, pp. 96-118, 2006.

[6] Kusrini and E. T. Luthfi, Algoritma Data Mining, Yogyakarta: ANDI, 2009.

[7] S. Wang and B. Meng, "Parameter Selection Algorithm for Support Vector Machine," Procedia Environmental Sciences, vol. 11, pp. 538-544, 2011.

[8] L. Yun, Q.-y. Cao and H. Zhang, "Application of the PSO-SVM model for Credit Scoring," Seventh International Conference on Computation Intelligence and Security, pp. 47-51, 2011.

[9] A. Heiat, "Modeling Consumer Credit Scoring Through Bayes Network," World Journal of Social Sciences, vol. 3, pp. 132-141, 2011.

[10] O. Maimon and L. Rokach, Data Mining and Knowledge Discovery Handbook, London: Springer , 2010.

[11] C. Grosan, A. Abraham and M. Chis, "Swarm Intelligence in Data Mining," Studies in Computational Intelligence (SCI), vol. 34, pp. 1-20, 2006.

[12] D. Aha and F. G. S. a. U. Irvine, "UCI Machine Learning Repository," Rexa.info, 2007. [Online]. Available: https://archive.ics.uci.edu/ml/about.html. 